Cite this: RSC Adv., 2014, 4, 18930

Received 11th March 2014 Accepted 1st April 2014

DOI: $10.1039 / c 4 r a 02420 f$

www.rsc.org/advances

\title{
Tuneable radical cyclisations: a tin-free approach towards tricyclic and spirocyclic heterocycles via a common precursor $\dagger$
}

\author{
B. Patel, G. Saviolaki, C. Ayats, M. A. E. Garcia, T. Kapadia and S. T. Hilton*
}

A novel common precursor approach towards both tricyclic and spirocyclic heterocycles is described. Cyclisations are based on thiyl radical/isocyanide methodology and avoid the use of tin.

Tricyclic heterocycles and their related spirocyclic congeners are attractive synthetic targets due to their occurrence in natural products and their frequent use as therapeutics. ${ }^{1}$ Nearly all members of these two distinct chemical series possess potent and widely differing biological activities and have attracted significant attention from both synthetic and medicinal chemists. ${ }^{1}$ In particular, martinelline $\mathbf{1}$ and martinellic acid $\mathbf{2}$ - isolated from the roots of Martinella iquitosensis, have featured frequently in the literature, due to their unique occurrence in nature and their antibiotic/antagonistic activity towards several G-protein coupled receptors (GPCR) systems including bradykinin and muscarinic receptors. ${ }^{2}$ Amongst the non-natural product based compounds, the related tricyclic molecule - NVPBEZ235 3, which is a dual inhibitor of $\mathrm{PI} 3 \mathrm{~K} / \mathrm{mTor}$ pathway serves to highlight the anticancer potential of this class of compound. ${ }^{3}$ Related to their tricyclic counterparts, the spirooxindole heterocycles have also attracted significant attention, not least due to their structural complexity. This ranges from simple members such as horsfiline $\mathbf{4}$ and coerulescine $5,{ }^{4}$ through to more substituted derivatives such as alstonisine 6 and spirotryprostatin A 7.5.6 There have been a significant number of synthetic efforts directed towards 7 and related derivatives due to its potent antinioplastic activity via inhibition of the cell cycle (Fig. 1). ${ }^{6}$

There have been several approaches to both these classes of compound using radical methodology as a result of the mild flexible and predictable conditions that can be used, preventing the need for protection/deprotection steps. ${ }^{7}$ In particular

UCL School of Pharmacy, 29-39 Brunswick Square, London, UK. E-mail: s.hilton@ucl. ac.uk; Fax: +44 (0)2077535964; Tel: +44 (0)2077535804

$\dagger$ Electronic supplementary information (ESI) available: Experimental details and characterisation of all compounds and copies of all spectra are available. See DOI: $10.1039 / \mathrm{c} 4 \mathrm{ra} 02420 \mathrm{f}$
Takeda et al. have reported an attractive radical route to the core structure of Martinelline, ${ }^{7}$ whilst Beckwith and Storey have developed a route towards oxindoles via hydrogen atom abstraction using tributyltin hydride. ${ }^{8}$ Despite the large number of reports towards both classes of compound, many rely upon the use of organo-tin hydride reagents as a way of mediating these processes. ${ }^{7,8}$ An alternative method for the formation of nitrogen heterocycles that avoids the use of tin involves the addition of thiyl radicals to isocyanides, generating $\alpha$-imidoyl radicals which can undergo cyclisation onto a pendant alkene/ alkyne. ${ }^{9}$ However, there is no approach that allows for the synthesis of both chemical classes commencing from a common precursor. We now wish to disclose a novel tuneable approach to both tricyclic and spirocyclic heterocycles that is able to select for both classes via simple modification of the reaction conditions. The disconnection sequence towards both the pyrroloquinoline core $\mathbf{8}$ and the spirocyclic structure $\mathbf{9}$ from reaction of the precursor $\mathbf{1 1}$ is shown in detail (Scheme 1).

We envisaged that under suitable reaction conditions the intermediate $\alpha$-imidoyl radical derived from addition of a thiyl radical to the isocyanide 11, would undergo either 6-endo or 5exo cyclisation to generate either the tricyclic core $\mathbf{8}$, or the spirocyclic structure 9 respectively. Our approach was inspired

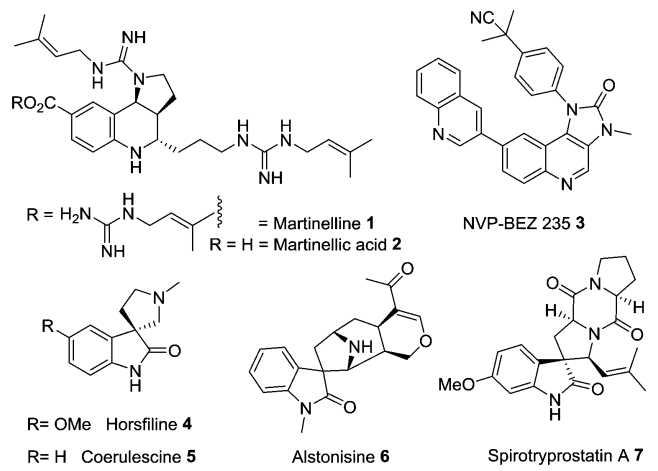

Fig. 1 Spirocyclic and tricyclic heterocycles. 
<smiles></smiles>

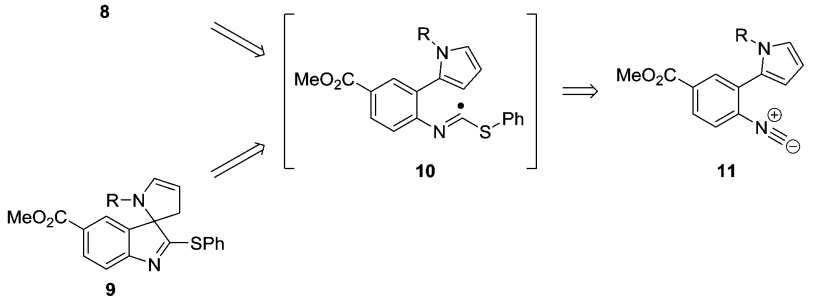

Scheme 1 Disconnection of the tricyclic and spirocyclic cores.

by the reports of Saegusa, Fukuyama and Rainier who had demonstrated precedent for 5-exo cyclisation, but there was limited evidence for successful obtention of the product of 6-endo cyclisation., ${ }^{9,10}$ The synthesis of the cyclisation precursor $\mathbf{1 1}$ commenced with iodination of methyl-4-aminobenzoate 12 to give the palladium coupling precursor 13 in $80 \%$ yield. ${ }^{11}$ Use of Suzuki-Miyaura conditions for the formation of amine $\mathbf{1 5}$ proved problematic with commercially available $N$-Boc-pyrrole2-boronic acid 14. However, switching to the use of freshly prepared 14 following the procedure of Martina, ${ }^{12}$ amine 15 was obtained in $82 \%$ yield. Subsequent formylation with formic acetic anhydride, ${ }^{\mathbf{1 3}}$ followed by dehydration with phosphorus oxychloride and diisopropylamine proceeded smoothly, resulting in isocyanide $\mathbf{1 1}$ in $\mathbf{7 9 \%}$ yield (Scheme 2). ${ }^{\mathbf{1 4}}$

With the cyclisation precursor 11 in hand, investigation of a range of conditions were explored in order to select for either 6-endo or 5-exo cyclisation in a thermodynamic or kinetic manner respectively and the results are outlined below (Table 1 ).

Evaluation of the effects of reaction concentration (Table 1, entries 1-3) on the ratio of $\mathbf{8}$ and $\mathbf{9}$, showed that only the 6-endo product 8 was formed at higher concentrations, but under more dilute conditions (entries 3-4), the ratio of $8: 9$ changed to a more favorable $11: 89$ ratio of the two products. At this point, it was evident that the reaction was tunable and either the product of 5-exo or 6-endo addition could be readily selected. Simple variation of the amount of AIBN (Table 1, entries 4-8), whilst the amount of thiophenol and the reaction concentration were kept constant also insinuated that the radical cyclisation could be tuned easily. The kinetic 5-exo spirocycle was favoured at higher concentrations of AIBN, suggesting that the cyclised product is

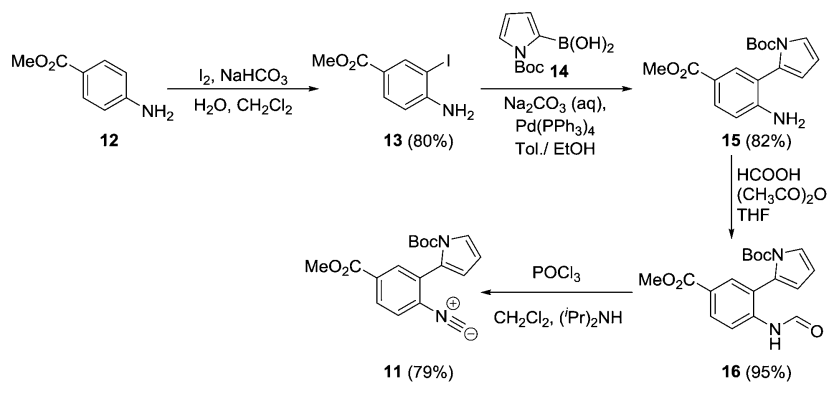

Scheme 2 Synthesis of common cyclisation precursor 11.
Table 1 Optimisation of reaction conditions for obtention of both tricyclic and spirocyclic heterocycles 8 and 9 respectively ${ }^{a}$

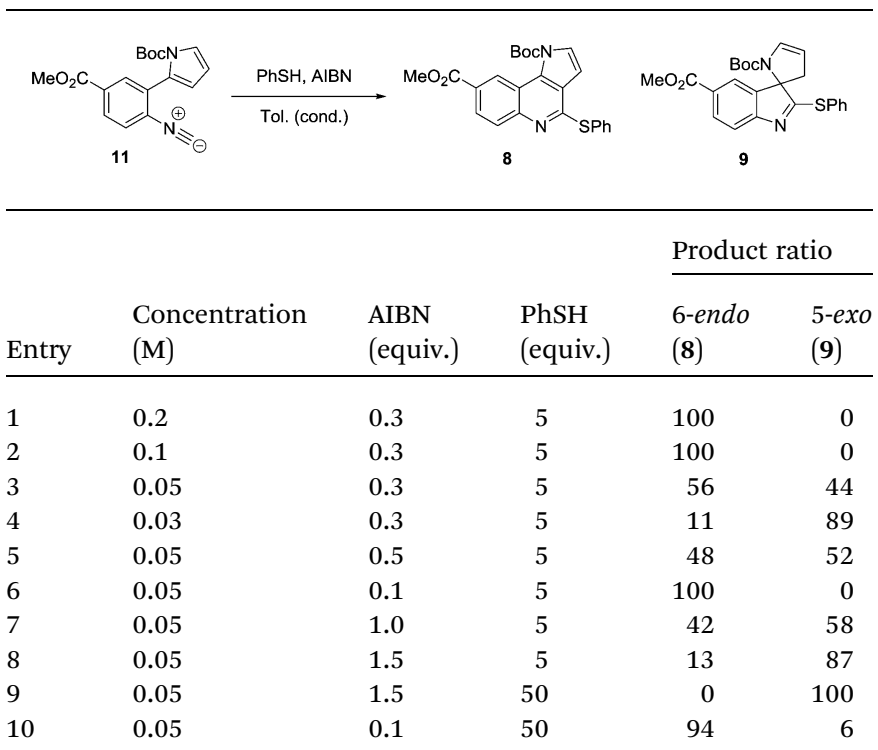

${ }^{a}$ Ratios of $\mathbf{8}$ and $\mathbf{9}$ were determined from the ${ }^{1} \mathrm{H}$-NMR spectrum of the crude reaction mixture. All reactions were carried out at $80^{\circ} \mathrm{C}$ in toluene for 2 hours by direct addition of reagents.

rapidly trapped and that the reaction itself is reversible. However, when the concentration of AIBN is low, the rate of cyclisation and subsequent reduction is slow and accordingly, the more stable thermodynamic 6-endo product predominates. To confirm the effects of the equivalents of AIBN on the reaction outcome, a large excess of thiophenol was used whilst varying the amount of AIBN (Table 1, entries 9 and 10). There was little difference on the reaction outcome when 50 equivalents of thiophenol were used, with selectivity easily tuned for either 5-exo or 6-endo addition.

With confirmation that the equivalents of AIBN and reaction concentration were critical, the reaction was carried out on a larger scale to fully isolate and characterise both products. As predicted, the tricyclic heterocycle 8 was obtained in $62 \%$ isolated yield when the reaction was carried out with 0.1 equivalents of AIBN. On repeating the reaction, but with conditions tuned for the synthesis of the spirocyclic product, compound 9 was isolated in $47 \%$ yield. A second product - 17 was also observed following purification, which corresponded to the double bond isomer, in $18 \%$ yield, from the parent compound 9. On contact with silica, the double bond undergoes a 1,3-hydride shift to give 17 and both products in a combined yield of $64 \%$ (Scheme 3 ).

In summary, we have developed a novel approach towards the synthesis of pyrroloquinoline and spirocyclic heterocycles using tin-free radical methodology, starting from a common precursor. This short flexible reaction sequence will provide a rapid approach to structurally diverse compounds of significant interest and the application of this methodology is currently under active investigation using other heterocyclic motifs. Examination of their corresponding biological effects and the results obtained will be reported in due course. 


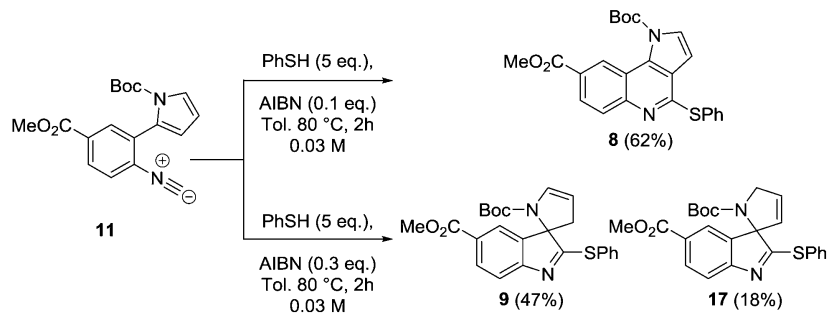

Scheme 3 Selection for 6-endo or 5-exo cyclisation.

\section{Acknowledgements}

This work was gratefully supported by the first grant scheme from the EPSRC [EP/J01544X/1], and a PhD studentship from UCL School of Pharmacy. We thank the EPSRC UK National Mass Spectrometry Facility at the Swansea University for spectroscopic services.

\section{Notes and references}

1 (a) A. I. S. Almeida, A. M. S. Silva and J. A. S. Cavaleiro, Synlett, 2011, 2955; (b) Y. Hamada, Chem. Pharm. Bull., 2012, 60, 1; (c) H. Benakki, E. Colacino, C. André, F. Guenoun, J. Martinez and F. Lamaty, Tetrahedron, 2008, 64, 5949; (d) M. Nyerges, Heterocycles, 2004, 63, 1685; (e) M. L. Testa, L. Lamartina and F. Mingoia, Tetrahedron, 2004, 60, 5873; (f) T. Stalling and J. Martens, Synthesis, 2013, 355; $(g)$ Q. Zhang, M. Ding, Z. Cao, J. Zhang, F. Ding and K. Ke, Neurochem. Res., 2013, 38, 1661; (h) T. Li, H. Yin, C. Yao, X. Wang, B. Jiang, S. Tu and G. Li, Chem. Commun., 2012, 48, 11996; (i) C. Marti and E. M. Carreira, Eur. J. Org. Chem., 2003, 2209.

2 (a) K. M. Witherup, R. W. Ransom, A. C. Graham, A. M. Bernard, M. J. Salvatore, W. C. Lumma, P. S. Anderson, S. M. Pitzenberger and S. L. Varga, J. Am. Chem. Soc., 1995, 117, 6682; (b) M. K. Gurjar, S. Pal and A. V. R. Rao, Heterocycles, 1997, 45, 231; (c) B. B. Snider, Y. Ahn and B. M. Foxman, Tetrahedron Lett., 1999, 40, 3339; (d) C. J. Lovely and H. Mahmud, Tetrahedron Lett., 1999, 40, 2079; (e) O. Hara, K. Sugimoto and Y. Hamada, Tetrahedron, 2004, 60, 9381; $(f)$ R. Le Goff, A. M. Lawson, A. Daïch and S. Comesse, Org. Biomol. Chem., 2013, 11, 1818; $(g)$ M. Hadden, M. Nieuwenhuyzen, D. Osborne, P. J. Stevenson, N. Thompson and A. D. Walker, Tetrahedron, 2006, 62, 3977; (h) C. Xia, L. Heng and D. Ma, Tetrahedron Lett., 2002, 43, 9405.

3 F. D. R. Stauffer, S.-M. Maira, et al., Bioorg. Med. Chem. Lett., 2008, 18, 1027.

4 (a) S. Hong, M. Jung, Y. Park, M. W. Ha, C. Park, M. lee and H. Park, Chem.-Eur. J., 2013, 19, 9599; (b) E. Rajanarendar, S. Ramakrishna, K. G. Reddy, D. Nagaraju and Y. N. Reddy, Bioorg. Med. Chem. Lett., 2013, 23, 3954; (c) Y. Arun,
G. Bhaskar, C. Balachandran, S. Ignacimuthu and P. T. Perumal, Bioorg. Med. Chem. Lett., 2013, 23, 1839; (d) J. A. Murphy, R. Tripoli, T. A. Khan and U. W. Mali, Org. Lett., 2005, 7, 3287; (e) M. Görmen, R. Le Goff, A. M. Lawson, A. Daïch and S. Comesse, Tetrahedron Lett., 2013, 54, 2174; ( $f$ ) A. Jossang, P. Jossang, H. A. Hadi, T. Sévenet and B. Bodo, J. Org. Chem., 1991, 56, 6527; $(g)$ N. Anderton, P. A. Cockrum, S. M. Colegate, J. A. Edgar, K. Flower, I. Vit and R. I. Willing, Phytochemistry, 1998, 48, 437; (h) S. Bascop, J. Sapi, J. Laronze and J. Lévy, Heterocycles, 1994, 38, 725.

5 J. Yang, X. Z. Wearing, P. W. Le Quesne, J. R. Deschamps and J. M. Cook, J. Nat. Prod., 2008, 71, 1431.

6 (a) C. Cui, H. Kakeya and H. Osada, Tetrahedron, 1996, 52, 12651; (b) A. P. Antonchick, H. Schuster, H. Bruss, M. Schürmann, H. Preut, D. Rauh and H. Waldmann, Tetrahedron, 2011, 67, 10195; (c) M. Cheng, H. Wang and L. Gong, Org. Lett., 2011, 13, 2418; (d) F. Y. Miyake, K. Yakushijin and D. A. Horne, Org. Lett., 2004, 6, 4249; (e) T. Onishi, P. R. Sebahar and R. M. Williams, Tetrahedron, 2004, 60, 9503; (f) S. Edmondson, S. J. Danishefsky, L. Sepp-Lorenzino and N. Rosan, J. Am. Chem. Soc., 1999, 121, 2147.

7 (a) S. T. Hilton, T. C. T. Ho, G. Pljevaljcic and K. Jones, Org. Lett., 2000, 2, 2639; (b) C. Escolano and K. Jones, Tetrahedron, 2002, 58, 1453; (c) O. Miyata, A. Shirai, S. Yoshino, T. Nakabayashi, Y. Takeda, T. Kiguchi, D. Fukumoto, M. Ueda and T. Naito, Tetrahedron, 2007, 63, 10092; (d) T. Naito, Pure Appl. Chem., 2008, 80, 717; (e) T. C. T. Ho and K. Jones, Tetrahedron, 1997, 53, 8287.

8 A. L. J. Beckwith and J. M. D. Storey, J. Chem. Soc., Chem. Commun., 1995, 977.

9 (a) J. D. Rainier and A. R. Kennedy, J. Org. Chem., 2000, 65, 6213; (b) D. Nanni, G. Calestani, R. Leardini and G. Zanardi, Eur. J. Org. Chem., 2000, 707; (c) M. D. Bachi, A. Balanov and N. Bar-Ner, J. Org. Chem., 1994, 59, 7752; (d) K. C. Majumdar and P. Debnath, Tetrahedron, 2008, 64, 9799; (e) M. Lamberto and J. D. Kilburn, Tetrahedron Lett., 2008, 49, 6364; (f) M. Lamberto, D. F. Corbett and J. D. Kilburn, Tetrahedron Lett., 2004, 45, 8541.

10 (a) T. Fukuyama and G. Liu, Pure Appl. Chem., 1997, 69, 501; (b) H. Tokuyama, M. Watanabe, Y. Hayashi, T. Kurokawa, G. Peng and T. Fukuyama, Synlett, 2001, 1403; (c) T. Saegusa, S. Kobayashi and Y. Ito, J. Org. Chem., 1970, 35, 2118.

11 A. G. Arvanitis, P. J. Gilligan, et al., J. Med. Chem., 1999, 42, 805.

12 S. Martina, V. Enkelmann, G. Wegner and A. Schlüter, Synthesis, 1991, 613.

13 T. G. Back, M. Parveez and J. E. Wulff, J. Org. Chem., 2003, 68, 2223.

14 R. Obrecht, R. Hermann and I. Ugi, Synthesis, 1985, 400. 